\title{
Jurandy surfa sobre um Jacaré tocando o bolero de Ravel
}

\author{
Heloísa de Araújo Duarte Valente \\ Doutora; Universidade Paulista, São Paulo, SP, Brasil \\ musimid@gmail.com
}

\begin{abstract}
Resumo
A partir do estudo do conhecido "pôr-do-sol na Praia do Jacaré" (Cabedelo - PB), ao som do Bolero, de Ravel, invenção do músico conhecido como Jurandy do Sax, pretende-se abordar as formas de apropriação da obra musical, transformada em objeto de consumo turístico. Para tanto, analisar-se-á como se dá o processo de movência da obra de Ravel, a partir de distintas formas de apropriação, performances e concepções estéticas da obra. Em seguida, descrevem-se as estratégias adotadas por Jurandy, que funcionam como elementos simbólicos de reforço na sua forma de interação com o público. Paralelamente, ressalta-se a criação de Jurandy como o estabelecimento de uma paisagem sonora peculiar. Dentre as conclusões, destaca-se a importância do músico na autopromoção de seus produtos, além da criação de um filão de consumo midiático da música pelo turismo.
\end{abstract}

\section{Palavras-chave}

Paisagem sonora. Cartão postal sonoro. Entretenimento. Bolero de Ravel. Performance.

\section{A natureza, segundo as paisagens sonoras imaginadas e suas trilhas sonoras}

Numa interessante coluna jornalística semanal, o psicanalista Contardo Calligaris (2010) discorre sobre os sentimentos despertados ao pôr-do-sol. Recorre a artistas (Oscar Wilde, William Turner, Jean-François Millet, Dante) para sustentar a ideia de que o entardecer pode despertar o sentimento de solidão: "Somos, portanto, especialmente sensíveis ao fim do dia, cujo espetáculo acarreta consigo a lembrança dolorosa do fim de nossa jornada, que se aproxima." (CALLIGARIS, 2010, doc. não paginado). E prossegue o autor: No Angelus (1859), de Millet, vê-se um casal de camponeses que, ao escutar o campanário da igreja, percebe que o dia acabou e que é hora de ir rezar. 0 espaço aberto do campo, povoado pelo silêncio e pelos sons naturais é cortado pelo ruído que controla a rotina e a ordem social: o campanário da igreja. Mas, ao contrário de mensagem de paz, o 
Angelus vespertino é inquietante, lembra Calligaris (2010), pois só pode trazer a paz “[...] para quem tem uma casa para a qual voltar. Para os outros, é o sinal melancólico de uma perda sem remédio." (CALLIGARIS, 2010, doc. não paginado).

Em oposição à vida singela e monótona, regida pela rotina - iconizada no quadro de Millet - muita gente trocou a tranquilidade do campo pela vida frenética cidade. E esse movimento teria sua origem já no Renascimento, no período das grandes navegações, ganhando força no final do século XIX. O fato é que a industrialização levou as metrópoles a um crescimento desenfreado, e o êxodo do campo para a cidade passou a fazer parte da rotina do cidadão comum. Como consequência, o sentimento de desenraizamento tornou-se uma constante ${ }^{1}$.

Calligaris (2010) ressalta, ainda, que a circulação e a viagem estimulam os sentidos, mas, em contrapartida, a vida em trânsito - resultado da possibilidade de autonomia - tende a instaurar a nostalgia de um mundo (passado) que ficou para trás: aquele lar que nos esperaria ao final da tarde, afagando e confortando o final do dia, tal como mostra o quadro de Millet. A condição de viajante pagaria seu preço: o sentimento de perda.

O crepúsculo azuláceo, observado por Calligaris (2010), no saguão de embarque do aeroporto terá sido diverso de muitos outros, igualmente observados atentamente, em diferentes longitudes e latitudes. Pelas lentes de Carlos Saura, é dourado, tal como o percebemos na abertura do filme Tangos (1998). Muito possivelmente, o diretor espanhol ter-se-ia inspirado nas descrições de J. L. Borges, para quem os entardeceres e noites de Buenos Aires são essenciais para a existência do tango (VALENTE, 2003). Acrescente-se, ainda, que a luz e a luminosidade oscilam com as estações do ano, assim como as latitudes propiciam diferentes formas de percepção do mundo visível.

De fato, os espetáculos da natureza há séculos inspiram criações artísticas das mais diversas. No caso da música, sobretudo do romantismo, gêneros foram criados para serem apreciados em períodos específicos do dia. O noturno, por exemplo, foi concebido instrumental (pianístico, sobretudo) para ser executado nesse período da jornada, quando o crepúsculo se esvai e os últimos fiapos de luz se desvanecem. Despontam, então, a lua e as estrelas, no céu limpo e claro. Quantos terão sido os poemas e obras inspiradas pelo luar e o brilho das estrelas? De Clair de lune, (Debussy), Chão de estrelas (Orestes Barbosa), Noite cheia de estrelas (Cândido das Neves), Lua, lua, lua (Caetano Veloso) os exemplos são incontáveis...

\footnotetext{
${ }^{1}$ Este será um dos temas majoritários expressos nas letras da canção popular urbana das primeiras décadas do século XX (VALENTE, 2003).
} 
Para além de estabelecer hábitos de fruição cultural e de contemplação, o espetáculo da natureza pode se converter facilmente em produto para consumo imediato, em mercadoria, desde que planejado com competência. É o caso do pôr do sol na praia fluvial do Jacaré, em Cabedelo, município vizinho a João Pessoa, seus luais ${ }^{2}$ e eventos a ele posteriormente agregados. 0 chamariz, no caso, é a sincronização do evento natural com um espetáculo performático, dirigido ao turismo local. É sobre esse assunto que este texto se debruça, estabelecendo relações entre paisagem sonora, repertórios musicais, performance, consumo e memória no âmbito de uma cultura midiática.

\section{Assistindo ao pôr-do-sol na praia que não parece praia}

É típico do homem intervir na natureza, transformando-a, continuamente; a cada dia que passa, parece mais difícil encontrá-la em estado bruto, virgem, selvagem. Mentes inventivas sabem tirar proveito desses espaços, então disponíveis para por em prática suas iniciativas, notadamente, empresariais e, não raro inusitadas, a ponto de transformar localidades desconhecidas do mapa em polos de consumo. Este é o caso do pôr-do-sol na praia fluvial do Jacaré, com a execução do Bolero, de Ravel- invenção do músico José Jurandy Félix, conhecido como Jurandy do Sax. 0 evento de natureza performática atrai cada vez mais um número crescente de visitantes, a ponto de se estabelecido, como uma tradição; mais que isso, passeio que não deve faltar no roteiro do turista que visita a capital paraibana.

Nosso interesse particular no estudo de paisagens sonoras e musicais, suas implicações com fenômenos midiáticos - sobretudo aqueles que se transformam em rituais calendarizados despertaram nosso interesse, a ponto de nos motivar observar in loco o evento. Posteriormente, buscamos informações sobre o músico. A maioria delas é de natureza jornalística e em tom laudatório. Procuramos saber, através de colegas de profissão que teriam sido professores do músico acerca do seu currículo.

A origem do atrativo turístico é descrita pelo próprio Jurandy, em entrevista ao apresentador Jô Soares, em 13 de setembro de 2011 (FELIX, 2011). Dentre trivialidades, Jurandy expõe dados sobre o evento que se tornou, segundo ele, "a maior atração de João Pessoa" (FELIX, 2011). Dentre comentários um tanto maldosos e "provocações engraçadinhas", acerca do número de apresentações da obra e outras amenidades, o entrevistador indaga sobre a gênese da ideia. Jurandy então destaca a "magia do lugar" e seu hábito de há mais de 30 anos ir contemplar o pôr do sol no local (FELIX, 2011). Certo dia -

\footnotetext{
2 A palavra vem do havaiano lu'au, designando festas ao ar livre, com comida e inspiraram, no pós-guerra, as festas tiki-pop.
} 
relata o saxofonista - coincidiu o fato de o casal proprietário do Jacaré Bar desejar escutar a trilha (sic) do filme Retratos da Vida ${ }^{3}$ o Bolero, de Ravel ${ }^{4}$. Assim Jurandy atendeu à vontade do casal, repetindo a mesma experiência em 1993, quando escolheu o local para lançar o disco Saxomania. A partir de 1999, passou a tocar quase que diariamente. Acrescenta que, no ano 2000, ao observar o crepúsculo, "aquela beleza toda", viu-se dentro d'água, afirma o saxofonista. Aí "recebeu a mensagem" de que iria tocar dentro (sic) d'água. Passados dois anos, o evento já havia crescido de maneira vultosa. Foi assim que, pouco a pouco, foram se acercando outros comerciantes, à beira-rio, até se tornar a atração que mais chama turistas ao estado da Paraíba, no dizer do instrumentista, já tendo ultrapassado $5300^{5}$ apresentações. A repercussão do evento levou o músico à França, a convite do prefeito de Levallois, como gesto de agradecimento à divulgação da música francesa e, em particular, da cidade em que viveu Ravel. Jurandy confessa ter sentido "um friozinho na barriga", ao tocar ao pé do túmulo de Ravel. 0 Programa exibe um vídeo, com o músico executando o tema em uníssono, com a banda sonora do filme. 0 baterista Miltinho acompanha o saxofonista, em um breve dueto.

\section{Jurandy do Sax ${ }^{\circledR}$}

De acordo com informações anunciadas em sua página pessoal na Internet ${ }^{6}$ (JURANDI..., [2018]), Jurandy iniciou sua carreira profissional como músico, atuando em festas e bailes. Além do clarinete e do saxofone, desenvolveu habilidades em bateria, guitarra e baixo elétricos e canto. Exerceu a carreira militar, como músico, alcançando o posto de segundo sargento-músico na Banda da Polícia Militar, como primeiro clarinete solista. Atuou na Orquestra Sinfônica Jovem do Estado da Paraíba, por um breve período, uma vez que a carreira militar exigia dedicação exclusiva de seu efetivo. ${ }^{7}$ Desligou-se da Corporação em 1988, passando a passando a integrar Orquestra de Frevos do Maestro Vilô. Mais tarde, diplomou-se pela Universidade Federal da Paraíba (UFPB), obtendo o título de bacharel em

\footnotetext{
${ }^{3}$ O título original da obra é Les uns et les autres (1981) dirigida por Claude Lelouch.

${ }^{4}$ Maurice Ravel (1875- 1937) é de ascendência basca por parte de mãe e suíça, pelo lado paterno. Além do Bolero (1928), muitas obras do compositor fazem alusão à Espanha, como Alborada del gracioso, Hora espanhola, Rapsódia espanhola.

${ }^{5}$ Até a conclusão deste trabalho, não foi possível encontrar informação de fonte segura e atual que confirme a afirmação do músico. Esta é a informação prestada pelo entrevistado.

${ }^{6}$ Também na rede social Facebook: https://www.facebook.com/JurandydoSaxpb. Uma nova consulta aponta que a página sofreu ligeiras mudanças, o blog sendo o local com informações atualizadas sobre apresentações e produtos para venda. Consulta: 10 out.2015. Em 8 de agosto de 2020, há 12199 curtidas é de 1204 seguidores. A participação no Programa do Jô ocorreu quando o número de execuções girava em torno de 4000. Um crescimento mais lento nesta rede social revela a migração dos seguidores para o Twitter.

${ }^{7}$ Uma informação paralela, que nos foi passada por um ex-professor na Universidade atesta que seu talento musical e dedicação ao curso não eram compatíveis com o desejado. Em se tratando de conversa reservada e a fim de não expor a fonte, evitamos mencionar nomes. Por e-mail, 05 out2015 e endossado em 28 maio 2017.
} 
Música/instrumento (clarinete). A partir de 1992, passou a dedicar-se ao saxofone.A página na Internet do músico compõe-se das seções: Home; serviços; Instagram; imprensa e redes (Twitter, Youtube, Instagram, Pinterest) que inclui, dentre outros, a galeria de eventos, com mais de 470 fotografias. Através do portal, é possível conhecer as atividades profissionais do músico, bem como contratar seus serviços. Consultando novamente a página do músico, no dia 10 de outubro de 2015, encontra-se o aviso: "Hoje farei a apresentação 5440" (do Bolero) ${ }^{8}$. Pelo portal é possível é possível monitorar quem está online em tempo real. E na interface do Facebook (JURANDY..., [2018]) -, em que o empresário que conta com 11268 curtidas $^{9}$ - observa-se, no canto direito da tela, um alerta: não existem mais os restaurantes que cobravam couvert artístico; agora é possível ver sem ter de pagar! Mas se quiser comprar o ingresso para o catamarã, contrate aqui...Dentre os feitos a se destacar, na carreira do saxofonista, inclui-se a participação no Ano do Brasil na França ${ }^{10}$. Há imagens do músico tocando em Paris, no Campo de Marte, com a Torre Eiffel ao fundo; outra fotografia o mostra em pé, numa lancha fazendo um tour pelo Sena. Sobre isso, faz-se pertinente um breve comentário. Essa combinação de imagens evidentemente tem como função primordial atestar a competência do músico no seu ofício, o padrão internacional sua carreira; seu cosmopolitismo... E, o mais importante: o seu prestígio, selo de garantia de qualidade, sancionado pelos espectadores de passagem, justamente no país em que nasceu o autor do Bolero original, Maurice Ravel. Ao inserir fotografias de sua interferência na paisagem sonora parisiense, Jurandy chancela a excelência do seu currículo ${ }^{11}$. Ao aglutinar uma lista de elementos simbólicos, capital francesa cidade-luz - palco do Iluminismo, da modernidade que desencadeou nos anos loucos, na década de 1920 e, ao mesmo tempo, o peso da tradição da cultura letrada e da erudição - Jurandy converte tudo isso num gesto de reverência à sua pessoa (persona) e à sua atividade - ditada por forças do além (ele recebeu uma mensagem, recorde-se...).

A Paris da efervescência, do flâneur tão comentado por Charles Baudelaire, dá lugar ao músico passeante que imprime sua marca, sob a forma de um clichê musical, com duplo selo

\footnotetext{
${ }^{8}$ Uma participação como entrevistado no Programa do Jô ocorreu quando o número de execuções girava em torno de 4000 (FÉLIX, 2011).

9 Em sua página no Facebook há um registro de 11933 curtidas e 11810 seguidores, na busca atualizada em 27 mai 2017 . Em 10 jul. 2018 de 11895 curtidas e 11782 seguidores (JURANDY..., [2018]).

${ }^{10}$ Há pouco mais de um ano, quando escrevi a primeira versão deste texto, destaquei partes que hoje não mais existem: as seções Eu estive lá e Praia do Jacaré. Além da série de fotografias que descrevem em sequência o pôr-do-sol, incluíam-se imagens do músico tocando em Paris, no Campo de Marte, com a Torre Eiffel ao fundo e outra numa lancha que faz o tour pelo Sena. Estas se encontram agora dissolvidas na infinidade de fotografias e matérias jornalísticas que reproduz, sem citar a fonte, autor e data.

${ }^{11}$ Como alertamos no início, não há estudos especializados que atestem objetivamente seu domínio técnico como instrumentista.
} 
de origem: a peça orquestral se ressignifica, na paisagem do litoral paraibano, agregando consigo os traços do herói triunfante na capital do luxo e da intelligentsia...

\section{Bolero, de Ravel, segundo quatro concepções distintas}

Antes de se prosseguir com comentários sobre o empreendimento criado por José Jurandy Félix, cabem alguns esclarecimentos preliminares, sobre o saxofone, sobre o gênero bolero e, por fim, sobre a obra do compositor francês. Apoiados em Zumthor, acreditamos que os componentes da performance estabelecem diferenças semânticas e de recepção, razão pela qual optamos por apresentar quatro interpretações distintas, sob as batutas de Sergiu Celibidache, Gustavo Dudamel, André Rieu e Jurandy). Comecemos com algumas palavras sobre instrumento que traçou o destino do músico paraibano.

0 saxofone é um instrumento relativamente recente. Patenteado em 1846, pelo belga Antoine-Joseph Sax, 1814-1894, mais conhecido como Adolphe Sax, embora confeccionado em metal, enquadra-se no naipe das madeiras, assim como a flauta ${ }^{12}$. A semelhança não decorre apenas da sonoridade, mas também do seu projeto de construção, em que orifícios são abertos e fechados por intermédio de chaves, tal como ocorre com a flauta, o oboé ou o clarinete. A classificação corresponde à tessitura (extensão das alturas; frequências) ${ }^{13}$ : sopranino, soprano, contralto, tenor, barítono, baixo, contrabaixo. A nomenclatura é, pois, similar àquela empregada para a classificação da voz humana cantada. Embora constitua um dos principais instrumentos das agrupações jazzísticas, o instrumento vem sendo empregado por vários compositores da música de concerto, desde o período romântico, na música orquestral, por compositores tais como Ambroise Thomas, Georges Bizet, Jules Massenet (LAROUSSE, 1982: 1391).Em outra situação, ao timbre do saxofone foi atribuída a configuração semântica atrelada a situações de sensualidade erótica, quando não pornográfica. Esta associação vinculou o instrumento imediatamente como timbre preferencial para Muzak $^{14}$ em peças da dramaturgia ou publicitárias relacionadas ao mercado do sexo. Jurandy adota o saxofone contralto, o mais comum, talvez pela extensão das alturas ser mais próxima à voz cantada. Quanto ao bolero, que não se confunda o gênero canção (popular) latino-americano que gozou de grande popularidade nas décadas de 194050. De acordo com o Dicionário Larousse de la Musique, o bolero em questão é, antes disso, uma dança de origem espanhola, mormente andaluza, que surgiu pelo final do século XVIII. Foi mais precisamente essa dança que inspirou o compositor francês:

\footnotetext{
${ }^{12}$ Ressalte-se que o saxofone é um instrumento que se desmembra em sete tipos, de acordo com a extensão de alturas.

${ }^{13}$ Utilizando um linguajar do senso comum, poder-se-ia falar em alcance das notas musicais do mais agudo ao mais grave.

${ }^{14}$ Utilizando uma definição breve, referimo-nos à música-ambiente de toda e qualquer natureza.
} 
Derivada da seguidilha teria sido criada pelo bailarino de nome Cerezo: Acompanhada, em sua origem, de canto e castanholas, o bolero é composto de três estrofes sobre um movimento moderado em compasso 3/4. Modificações de ritmo no interior do ternário são possíveis. (GOLÉA, 1982, p. 172, tradução nossa).

Figura 1 - Fórmula rítmica do bolero

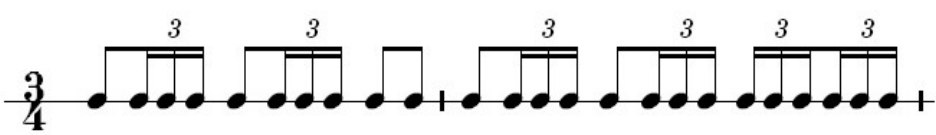

Fonte: Goléa (1982).

No verbete preparado para o o Dicionário Larousse, Antoine Goléa esclarece que o bolero se aproximou do fandango devido ao toque "cada vez mais nervoso" das castanholas. A fórmula rítmica foi adotada por compositores como Auber, Chopin, Albéniz e Ravel (GOLÉA, 1982, p. 172). Exposta esta advertência, passemos a uma análise mais detalhada do Bolero, de Maurice Ravel, composto em1928.

A peça teve sua estreia no dia 22 de novembro de 1928, na Ópera de Paris, sob a batuta de Walther Straram. Encomendada pela bailarina Ida Rubinstein seria, inicialmente, uma orquestração de obras de Albéniz. Ao invés disso, Ravel optou por escrever uma “([...] dança de um movimento bastante moderado e constantemente uniforme, tanto na harmonia, como no ritmo[...])" (RAVEL, 1983, p. 172). No entender de Jean Dupart, autor do verbete referente ao Bolero, de Ravel, a partitura constitui:

[...] ao mesmo tempo, uma teimosia insolente e um autêntico 'tour de force'. Ritmo e melodia são imutáveis, obsedantes, monótonos, mesmo. E é somente o jogo de timbres e o crescendo que a 'sustenta', do começo ao fim; desse jogo nascem os contrastes e a diversidade necessárias para o bom resultado da obra. A obra, conduzida por Ravel, com o esmero de um ourives, mas também com uma pitada de ironia levemente desdenhosa, começa com quatro compassos na introdução que, com a caixa-clara e as cordas, na região grave, são suficientes para a 'definir' o ritmo lancinante e o movimento imperturbavelmente regular de tempo di bolero. A primeira flauta enuncia o tema $\mathrm{A}$ em dó maior (articulado em dois períodos de oito compassos cada), que a clarineta toma, em seguida. (GOLÉA, 1982 p. 173, grifo do autor).

A concepção da obra de aparente simplicidade - uma massa sonora que ao longo de uma média de 17 minutos aumenta em intensidade e densidade culminando com o gran finale, marcado com o naipe da percussão e metais em fortíssimo. Este recurso extremamente eficaz, em termos comunicativos, esbanja em elementos poderosos, na 
semântica musical, com forte apelo ao gosto popular. Não será por acaso que terá se transformado em importante peça de repertório de orquestras as mais diversas...

Em assim sendo, a obra passou e vem passando por sucessivos processos de nomadismo (ZUMTHOR, 2005) que merecem ser comentados aqui. Ao falar de nomadismo fazemos referência à capacidade que o signo é dotado, permitindo-se traduzir a si próprio, ao longo do tempo, de maneira a garantir a sua sobrevivência - no caso presente, na paisagem sonora. Para que esse processo ocorra, a obra necessita ser dotada da capacidade de movência (ZUMTHOR, 1997), de modo a lhe permitir maleabilidade morfológica e contextual. Como poderemos assinalar, adiante, o processo de nomadismo não se restringe apenas aos elementos componentes da obra (arranjo, andamento etc.), mas também à sua forma intrínseca e condições transmissão e sua performance. Esta deve ser entendida não em sua acepção corriqueira, usual, mas como um conceito, elaborado pelo erudito Paul Zumthor (1997): a performance consiste num ato de enunciação de uma mensagem poética, tendo em conta não somente as condições de comunicação, mas também de transmissão, bem como as condições segundo as quais a mensagem é transmitida (ZUMTHOR, 1997).

Tratar de performance implica, pois, em estudar situações de deslocamento no tempo e no espaço, bem como suas implicações na percepção e no juízo estético. As variantes que compõem a performance, a concepção da obra - nas quais se incluem a sua difusão e formas de recepção - darão origem a outras formas de sensibilidade elaboradas pelo ouvinte/expectador. Para tornar a compreensão mais facilmente observável, tomarei como exemplo, dentre tantas versões à disposição, nas mais diversas mídias, casos de performances muito contrastantes, sob aspectos diversos: as versões do Bolero de Ravel, por Sergiu Celibidache (RAVEL..., 2011), Gustavo Dudamel (s/d), André Rieu (BOLÉRO..., 2012), além de Jurandy do Sax.

Dentre as inúmeras versões registradas do Bolero, em suas mais diversas mídias (televisão, cinema, disco etc.) podem-se estabelecer vários planos de análise. Existem as bem aceitas pelo público connaîsseur, que objetivam uma performance fidedigna à partitura e ao pensamento estético de Ravel sem, contudo, deixar de imprimir sua marca estilística. São justamente essas pequenas particularidades que conferem à obra formas de recepção e sensibilidade contrastantes.

Sergiu Celibidache: Uma versão televisionada, de 1971, pela Orquestra Nacional da Rádio Dinamarquesa, sob a batuta do maestro Sergiu Celibidache (RAVEL..., 2011) é bastante peculiar: percebe-se uma discreta desaceleração no andamento e, ao mesmo tempo, um fraseado com maior índice de contrastes na intensidade. Estes traços podem estabelecer 
uma relação normalmente associada a uma maior sensualidade no caráter geral da obra. Acrescente-se que na filmagem optou por revelar o maestro, ao invés da orquestra: incialmente, as mãos, nos primeiros compassos, seguida das expressões faciais, que vão do sorriso discreto, às vezes sugerindo cumplicidade dos músicos cede, após os doze minutos, para o tom enérgico. No finale, o bem-alinhado regente já se encontra descabelado e banhado em suor.

Figura 2 - Introdução

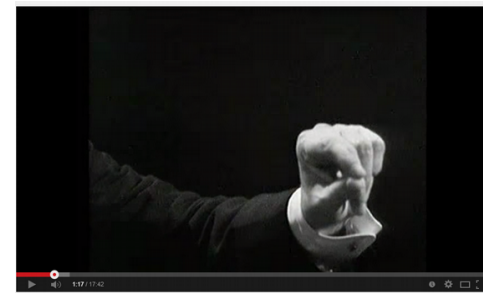

Fonte: Ravel - Bolero. Sergiu Celibidache 1971 (2011), adaptado pela autora.

Figura 3 - Exposição do tema

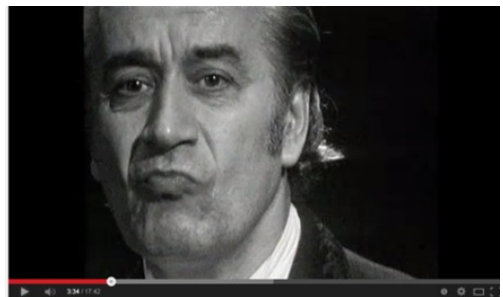

Fonte: Ravel - Bolero. Sergiu Celibidache 1971 (2011), adaptado pela autora.

Figura 4 - Reexposição do tema (tutti)

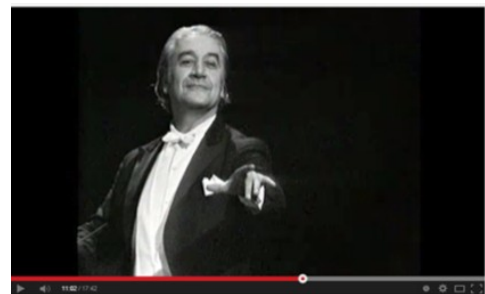

Fonte: Ravel - Bolero. Sergiu Celibidache 1971 (2011), adaptado pela autora.

Figura 5 - Finale

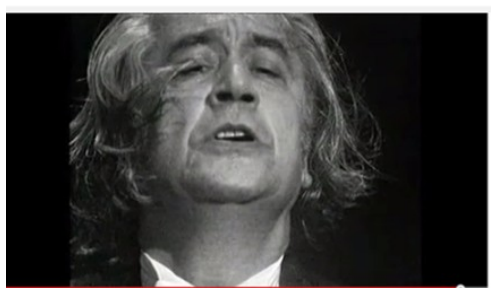

Fonte: Ravel - Bolero. Sergiu Celibidache 1971 (2011), adaptado pela autora. 
Gustavo Dudamel é um jovem regente venezuelano em ascensão na carreira profissional. Egresso d'El Sistema ${ }^{15}$. Diferentemente de outros colegas de profissão, desenvolveu uma relação diferente com a música, desembaraçando-a de uma associação da música de concerto a objeto de culto burguês, empoado e carregado de pompa vetusta. Praticar música consiste em atividade lúdica, educativa e mesmo prazerosa. Nesta filmagem, realizada pela rede de televisão franco-alemã Arte, percebe-se que o cinegrafista optou por dirigir a câmera aos instrumentos que entram em cena com o tema principal. 0 maestro só aparece por volta dos 13 minutos, quando da reexposição do tema. Percebe-se, então, a feição alegre e risonha que lhe é de praxe. Seus cabelos encaracolados desarranjam-se em todas as direções, ampliando os movimentos saltitantes que caracterizam a personalidade do regente. A despeito da gestualidade energética do maestro, a sua concepção da obra mantém o andamento moderato.

Figura 6 - Gustavo Dudamel e a Orquestra Filarmônica de Viena

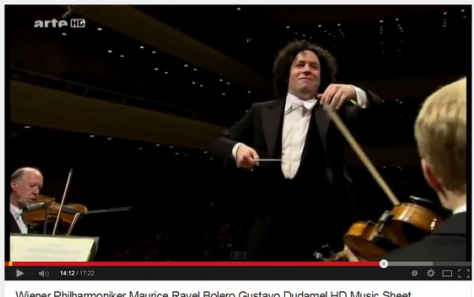

Fonte: WIENER Philharmoniker - Maurice Ravel - Bolero - Regente Gustavo Dudamel (2018), adaptado pela autora.

Figura 7 - Gustavo Dudamel e a Orquestra Filarmônica de Viena

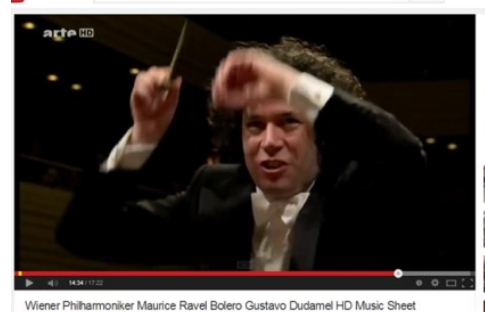

Fonte: WIENER Philharmoniker - Maurice Ravel - Bolero - Regente Gustavo Dudamel (2018), adaptado pela autora.

\footnotetext{
${ }^{15}$ Empreendimento fundado pelo músico e economista José Antonio Abreu. Através da Fundação Musical Simón Bolivar, criouse um movimento de formação de orquestras juvenis que serviria de modelo de ensino de música a crianças e jovens.
} 
Figura 8 - Gustavo Dudamel e a Orquestra Filarmônica de Viena

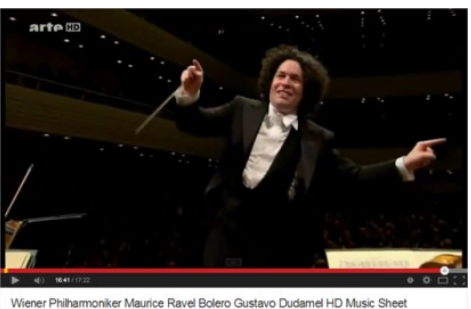

Fonte: WIENER Philharmoniker - Maurice Ravel - Bolero - Regente Gustavo Dudamel (2018), adaptado pela autora.

Figura 8 - Gustavo Dudamel e a Orquestra Filarmônica de Viena

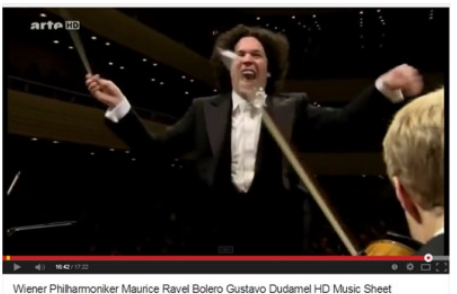

Fonte: WIENER Philharmoniker - Maurice Ravel - Bolero - Regente Gustavo Dudamel (2018), adaptado pela autora.

André Rieu: Face à sua grande popularidade, nos últimos anos, faz-se imperativo comentar, em termos comparativos, o caso particular do maestro André Rieu e a (sua) Orquestra Johann Strauss. O músico holandês consolidou-se na divulgação de peças de repertório romântico, em estilo apropriado para festas de gala. Os músicos seguem o mesmo padrão na indumentária, deixando de lado a austera casaca negra. Para além de homenagear o rei da valsa - o compositor austríaco que causou frisson nos salões palacianos do século XIX -, Rieu demonstra o desejo de querer reencarná-lo: o figurino é o elemento mais facilmente localizável na reconstituição do signo. Destaca-se, ainda, o violino que o regente empunha, sem necessidade performática, uma vez que, em alguns poucos compassos, chega a executá-lo. Trata-se antes de uma marca da construção da sua performance. Tudo o que mais se possa dizer acerca de sua versão do Bolero é extensível a outras peças do seu repertório.

Com o intuito de atingir o estilo grandiloquente, Rieu não poupa recursos - materiais e simbólicos. Nesse ponto, nem obra, nem compositor não escapam ilesos: instrumentos, coros e outros elementos são acrescidos (duplicados, triplicados...) - o que leva a obra a se transformar em outro signo, muito distante daquele idealizado pelo compositor. Frise-se que não se trata de arranjo ou readaptação, mas, antes de tudo, de uma quase que reinvenção ${ }^{16}$. Como já comentamos, o que torna o Bolero interessante é, justamente, o esmerado trabalho

\footnotetext{
${ }^{16}$ Não cabe nos limites deste texto uma avaliação mais aprofundada em torno do valor da obra ou mesmo dos procedimentos adotados por Rieu. Limitemo-nos ao caráter performático e sua eficácia comunicativa, sob o aspecto poético.
} 
com a criação de timbres sui generis. Para isso, Ravel combinou instrumentos pouco usuais na orquestra sinfônica moderna, tais como oboé d'amore, celesta, saxofone sopranino e tenor. Se assim o é, qual o papel das caixas-claras complementares, coro feminino, dentre outras fontes sonoras que Rieu inclui nos seus concertos?Alguns fotogramas capturados no excerto do DVD, divulgado pelo canal Youtube revelam a natureza dessas apresentações de Rieu e sua orquestra. Primeiramente, a transmissão ao ar livre, em espaços gigantescos, subdimensionados com a potência dos instrumentos da orquestra, torna obrigatória a inclusão de microfones e alto-falantes, dirigidos a uma plateia que, por sua vez, opta por conversar amenidades, enquanto a música é executada. Fazem-se necessário os canhões de luz que, por sua vez, destacam réplicas de templos gregos estilizados. Não sendo bastante, um naipe de percussionistas traveste-se de "garotos do tambor" ${ }^{17}$. Enfim, trata-se de um espetáculo sobrecarregado de elementos energizantes, para atender àqueles que buscam o entretenimento sem o valor agregado do prazer estético-musical.

Figura 9 - André Rieu e Johann Strauss Orchestra

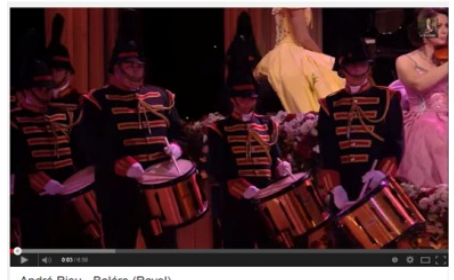

Fonte: Boléro (Ravel) - André Rieu (2012), adaptado pela autora.

Figura 10 - André Rieu e Johann Strauss Orchestra

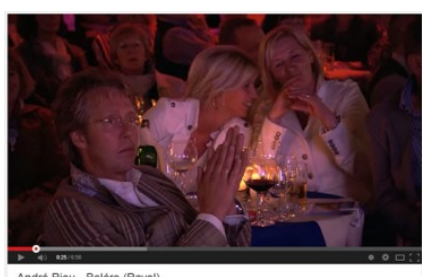

Fonte: Boléro (Ravel) - André Rieu (2012), adaptado pela autora.

Figura 11 - André Rieu e Johann Strauss Orchestra

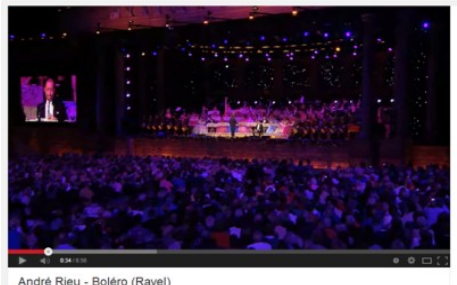

Fonte: Boléro (Ravel) - André Rieu (2012) adaptado pela autora.

\footnotetext{
${ }^{17}$ Durante muito tempo foi uso colocar meninos tocadores de tambor à frente das tropas militares, a fim de marcar o passo da caminhada da infantaria.
} 
Figura 12 - André Rieu e Johann Strauss Orchestra

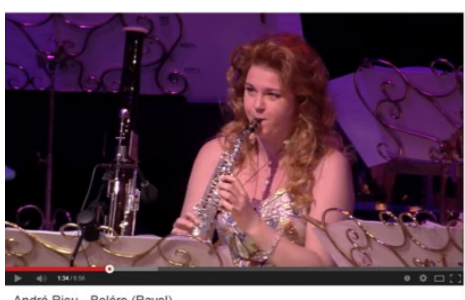

Fonte: Boléro (Ravel) - André Rieu (2012) adaptado pela autora.

Figura 13 - André Rieu e Johann Strauss Orchestra

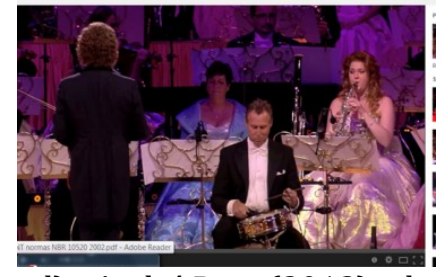

Fonte: Boléro (Ravel) - André Rieu (2012) adaptado pela autora.

Figura 14 - André Rieu e Johann Strauss Orchestra

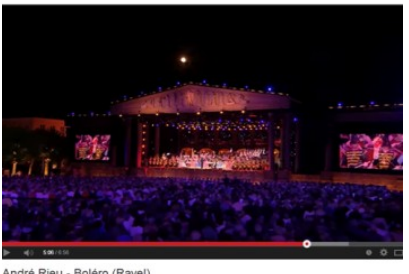

Fonte: Boléro (Ravel) - André Rieu (2012) adaptado pela autora.

Figura 15 - André Rieu e Johann Strauss Orchestra

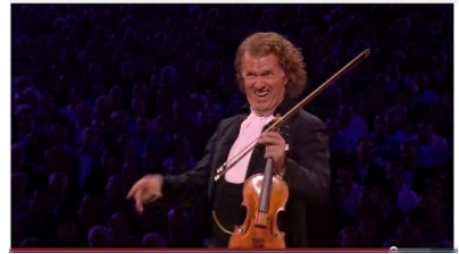

Fonte: Boléro (Ravel) - André Rieu (2012) adaptado pela autora.

Figura 16 - André Rieu e Johann Strauss Orchestra

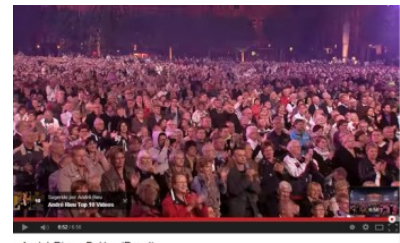

Fonte: Boléro (Ravel) - André Rieu (2012) adaptado pela autora. 
Figura 17 - André Rieu e Johann Strauss Orchestra

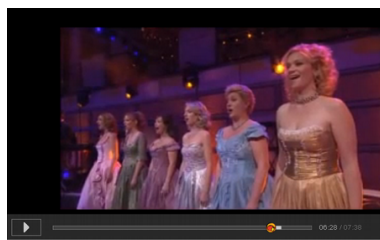

Fonte: Boléro (Ravel) - André Rieu (2012) adaptado pela autora.

Jurandy do Sax: Voltemos ao músico paraibano. Como já exposto, o insistente Bolero tem, como traços característicos fundamentais, a periodicidade e o jogo de timbres sui generis. No entanto, a execução do músico paraibano escapa radicalmente àquilo que preconizou o compositor: variações de andamento, inclusão de vibrato. Assim como a intensidade e a massa sonora não sofrem variações, o timbre mantém-se repetitivamente o mesmo - do saxofone, em playback, sem modulações, crescendi e decrescendi, acompanhado de uma gravação cuja fonte não é mencionada. Pelo ato da escuta, supõe-se que se trate de gravação digital, datada de menos de vinte anos.

Dessa ação decorre uma importante intervenção do saxofonista, no estatuto da peça: eliminando o que a obra tem de interessante: variações de densidade, e de intensidade. Jurandy costuma tocar à beira-rio, executando a parte orquestral em altos decibéis, em playback espalhada pelas caixas de som dos bares. Ocorre um interessante deslocamento espacial, à medida que o músico se afasta de seu público até alcançar a canoa.

Figura 18 - Jurandy do Sax em um habitual crepúsculo na praia fluvial do Jacaré

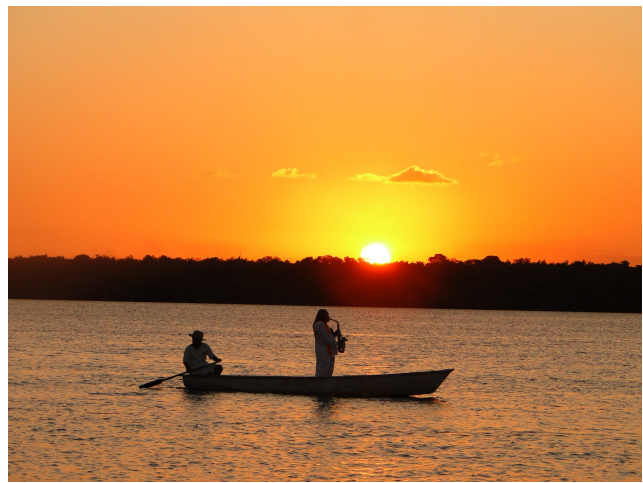

Fonte: Acervo pessoal Heloísa Valente. 
Figura 19 - Jurandy do Sax em um habitual crepúsculo na praia fluvial do Jacaré

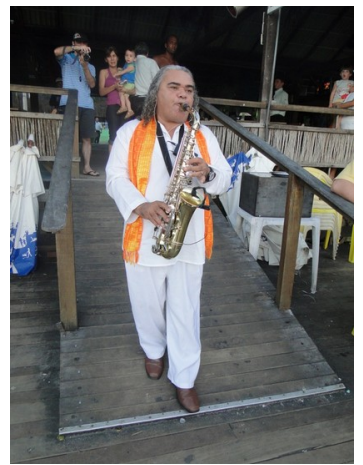

Fonte: Acervo pessoal Heloísa Valente.

Figura 20 - Jurandy do Sax em um habitual crepúsculo na praia fluvial do Jacaré

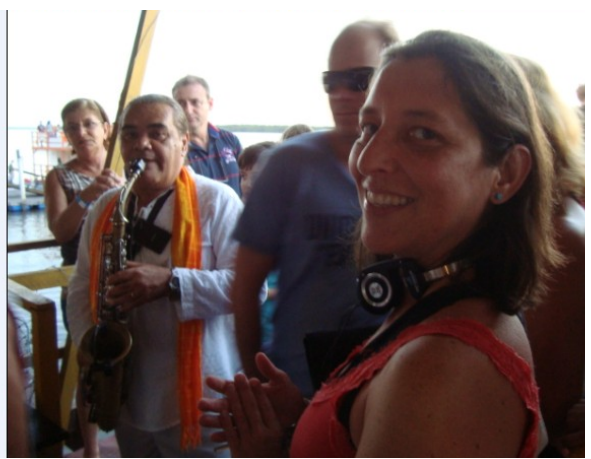

Fonte: Acervo pessoal Heloísa Valente.

Ainda que o aspecto da teatralidade pareça constituir o ponto de interesse principal de todos os intérpretes aqui mencionados, é notória a intenção de exacerbar o caráter monumental, nos dois últimos casos - o que, em grande medida, transborda para o kitsch. Se Jurandy busca entretenimento para os turistas de passagem, que correm sofregamente atrás de um cartão postal sonoro de efeito bomba, que os guias turísticos anunciaram algures, André Rieu procura atender a um público pagante de espetáculos pomposos, grandiosos, afeitos ao entretenimento fácil e de baixa exigência intelectual. Ao solicitar a excitação exagerada, o que o Bolero teria a revelar de interessante, perde totalmente o propósito. Há um deslocamento considerável entre o projeto composicional de Ravel e a realização performática de Jurandy. Não obstante, quem compra a excursão até a Praia, busca algo mais que uma experiência estético-musical.

Apresentados os quatro exemplos de performance da obra do mestre francês, podemos sintetizar, para além das particularidades dos maestros de caráter pessoal (escola de regência, personalidade, formação técnica, intelectual, idade etc.):

a) as versões de Celibidache (RAVEL..., 2011) e Dudamel (WIENER..., 2018) se inscrevem numa situação de performance e recepção do concerto de música erudita - não obstante este Bolero tenha se convertido em um clássico popular 
de fácil aceitação para o grande público. Rieu adota a ambiência dos concertos populares da Belle Époque vienense, introduzindo mudanças discretas na composição. A versão de Jurandy - em que pese sua admiração pela obra e pelo autor - é, antes de qualquer coisa, uma conversão em trilha sonora de um acontecimento da natureza;

b) em todos os casos, ocorrem situações diferenciadas de mediatização técnica: Célibidache conduz um concerto em gravação para a televisão; Dudamel rege a peça que encerra o concerto de Ano Novo; Rieu, de sua parte, tem o espetacular, com pompa e grandiosidade como marca registrada de seus concertos; Jurandy traz para si a incorporação simbólica do mago, que faz o sol se pôr, com o seu ato de tocar a obra de Ravel ${ }^{18}$;

c) muito embora todos os exemplos aqui analisados estejam presentes em sua forma mediatizada (vídeo), a obra foi concebida para ser tocada ao vivo, em teatro apropriado para música (lembremos que o timbre é a preocupação central do compositor e o aspecto mais interessante da obra). Cada etapa de introdução de meios tecnológicos audiovisuais acaba por constituir um processo de movência da obra;

d) não menos importante é considerar a época em que tais registros audiovisuais foram feitos e as condições tecnológicas à disposição, permitindo a recepção da obra em condições de maior ou menor fidelidade acústica - considerando a verossimilhança com o som emanado pela fonte sonora.

\footnotetext{
${ }^{18}$ De um modo geral, o paraibano potencializa a figura simbólica do sacerdote, já incorporada pelos regentes do romantismo. Este tema, ainda que relevante, não cabe nas dimensões deste texto. Fica aqui um aceno para uma futura abordagem, a esse respeito.
} 


\section{Cartão postal sonoro e cultura do entretenimento ${ }^{19}$}

Figura 21 - Arredores da praia do Jacaré

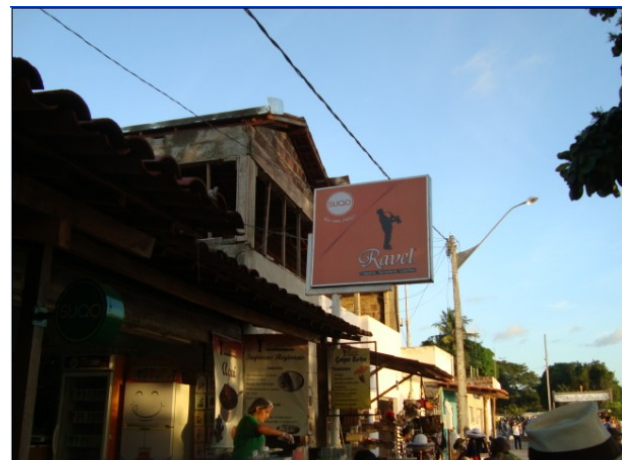

Fonte: Acervo pessoal Heloísa Valente.

Figura 22 - Arredores da praia do Jacaré

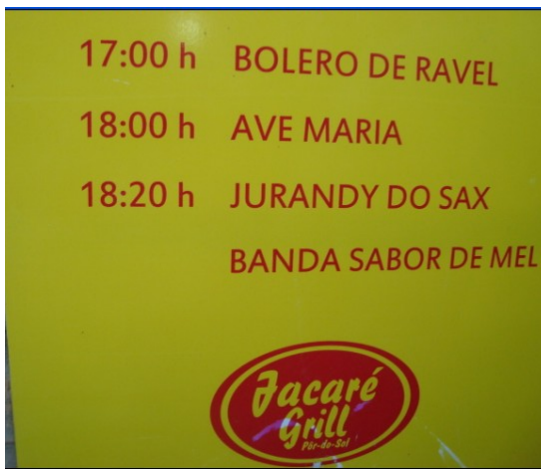

Fonte: Acervo pessoal Heloísa Valente.

Figura 23 - Arredores da praia do Jacaré

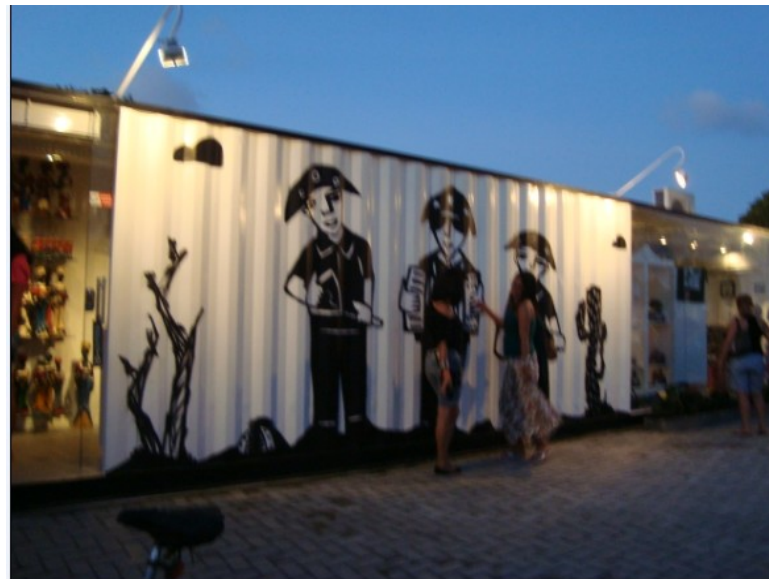

Fonte: Acervo pessoal Heloísa Valente.

${ }^{19}$ As observações que seguem resultam de duas visitas que fiz ao local, em dois anos seguidos. Em agosto de $2012 \mathrm{e}$ em maio de 2013. A primeira visita se deu num dia de semana; a segunda, num feriado. Apesar das características diferentes, como o maior número de frequentadores, no feriado, procurei analisar os elementos em comum. Pelo que constava, naquela época, no portal de Jurandy, na Internet, a configuração do espaço se alterou, tendo desaparecido os restaurantes à beira-rio e implantada uma praça de alimentação. Pelo que permitem avaliar as informações prestadas, Jurandy assenhoreou-se do local e controla grande parte das atividades lá realizadas, a começar pela vinculação de uma empresa turística que para lá arrebanha visitantes pagantes. 
Figura 24 - Arredores da praia do Jacaré

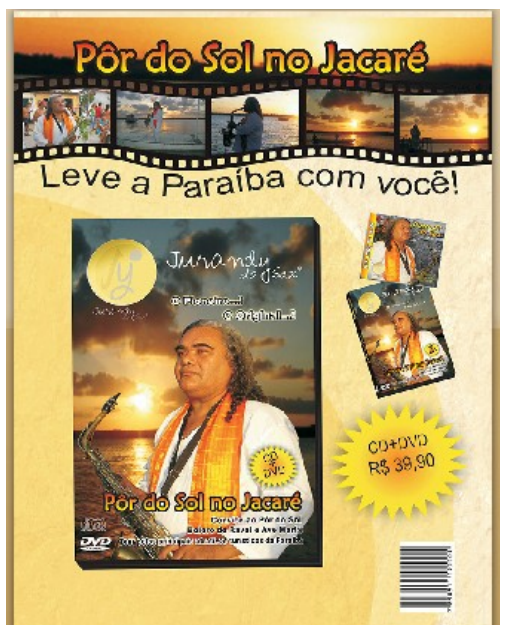

Fonte: Acervo pessoal Heloísa Valente.

Postos estes exemplos, parece mais fácil compreender como a iniciativa de Jurandy iniciada como uma atividade prazerosa e lúdica transformou-se em empreendimento inserido na indústria do entretenimento: do singelo ato de tocar ao pôr-do-sol ao estabelecimento de toda uma rede de comércio e serviços - ele próprio lançando e promovendo a sua marca, foram longos anos de uma atividade que fez crescer e impulsionar o turismo local - como já afirmamos, anteriormente.

Este cenário, contudo, não permaneceria o mesmo. Pouco tempo após a nossa visita, mudanças importantes vieram a ocorrer neste ponto turístico da Paraíba: uma reformulação radical necessária viria a ocorrer, uma vez que a área vinha sendo ocupada de maneira improvisada e ilegal. Após muitas tratativas e negociações ${ }^{20}$ ocorreu, de fato, a demolição, em agosto de 2015, como cumprimento de uma operação da Superintendência do Patrimônio da União no Estado da Paraíba (SPU-PB). Segundo informa o portal G1, da Rede Globo, em sua sucursal paraibana, as construções eram irregulares, em área da União e sem o licenciamento ambiental. Há projeto para criação de um parque. Na matéria, o secretário de turismo Omar Gama esclarece que inicialmente será reestruturada a região do mercado de artesanato, seguido do parapeito na área liberada após a extinção dos bares. Uma terceira etapa prevê a licitação para a ocupação e construção dos quatro novos restaurantes ${ }^{21} .0$ que se pode concluir, sinteticamente, sobre a invenção de Jurandy do Sax é que, para além da

\footnotetext{
${ }^{20}$ Em 4 de agosto de 2014, o músico protestou, nas redes sociais: “Hoje eu Fiz a apresentação de número 5.005, hoje eu finalizei minha apresentação antes do sol se por e me vesti de preto! LUTO, pelo que querem fazer com o maior atrativo turístico da Paraíba! O Ministério Público recomenda a SPU que retire os restaurantes instalados as margens do Rio Paraíba! Na praia do Jacaré. Se isso acontecer será um desastre para o turismo paraibano! Falei a todos os presentes. Mais de 2.000 pessoas! Falei dos motivos do meu protesto e convidei os prejudicados, a sociedade, o poder público e cobrei um pronunciamento do governador que se porta como se não estivesse acontecendo nada! Precisamos nos unir e lutar, não queremos continuar infringindo as leis ambientais! Mas, queremos solução e não destruição. Vamos à luta! A Paraíba não pode voltar no tempo! E o meu sax se recusa a calar!” (JURANDIR..., 2014).

${ }^{21}$ Não nos foi possível obter notícias a respeito do atual estado do local. Tomamos como referência a possibilidade de que as obras tenham sido concluídas e o parque reinaugurado, dada a importância turística do local.
} 
concepção musical planejada com o fim de engendrar um produto turístico apelativo, outros aspectos devem ser lembrados, a fim esclarecer o sucesso da empreitada. Referimo-nos aos elementos de imaginário incorporados e como estas atuam nas formas de comportamento que, por sua vez, passam por um processo de sedimentação pela cultura. Não sendo possível analisar detalhadamente todos eles, vale mencionar alguns deles:

0 corpo é a mídia primária (VALENTE, 2003) do músico: o uso da roupa branca, frequentemente associada, no âmbito da cultura ocidental a paz, limpeza, esterilização, pureza, candura. Os cabelos longos e ficam sempre presos, amarrados. A vestimenta soma elementos da cultura hippie com a simplicidade monástica. 0 músico marcha do Jacaré Bar até a canoa. Traça um caminho em linha reta no sentido tanto de ida quanto de volta. As pessoas ao redor o comportam-se como se fosse avistassem um beato ou mesmo homem santo. Ao entrar na canoa, percebe-se uma clara alusão ao episódio do Evangelho em que Cristo anda sobre as ondas do mar. 0 instrumento musical funciona como o objeto mágico (utensílio) que garante - antes que o princípio de Arquimedes - a flutuação sobre a água. 0 caráter reiterativo da música vem a contribuir para um estado hipnótico daquele que participa do evento.

É preciso enfatizar que este ritual calendarizado (todos os dias, em um horário preciso), com uma duração precisa: o último raio de luz deve coincidir precisamente com o último acorde do Bolero. Tudo isso deve acontecer ao vivo, em tempo real para que o teor mágico não seja perdido. Logo em seguida, este show de números tem continuidade com a apresentação de Belle Soares executa, ao violino, às 18h, quando executa a Ave Maria, de Gounod.

Cabem ainda algumas notas sobre a ocupação do espaço. 0 pôr-do-sol é um evento de João Pessoa, mas que não se encontra na capital paraibana. É um local que foi apropriado para esse fim. As visitas ao local mostraram, ao lado do Jacaré Bar outros, oferecendo serviços diferentes, repertórios musicais variados. (Mas sempre compostos de gêneros e sucessos da moda). Após a execução do Bolero, imediatamente iniciavam-se outras atividades, como shows de forró, bailes com alusão a Maria Bonita e Lampião, dentre outros. O comércio entrava em ação: artesanato, produtos locais (nordestinos) e souvenirs incluindo-se artigos exclusivos de Jurandy do Sax, uma vasta gama de produtos e quinquilharias convidando o turista a encher sacolas e levar como souvenirs de viagem. É de se supor que as atividades, ainda que tenham passado por adaptações na distribuição do espaço físico, permaneçam as mesmas...

A invenção do pôr-do-sol na praia do Jacaré parece ser, antes de tudo, empreendimento turístico voltado, sobretudo, a uma clientela de baixo poder aquisitivo, que 
compra entretenimento sob a forma de pacotes turísticos, em largas prestações -pelo menos estas foram as impressões colhidas durante a visita e cotejadas posteriormente, através de informações colhidas com outros visitantes de passagem que chegaram ao nosso conhecimento. Dentre as quinquilharias a trazer na bagagem de volta, encontra-se a experiência do anoitecer com o Bolero, de Ravel e outros produtos lá oferecidos.

É de se avaliar se o DVD, o CD de Jurandy, de Belle, ou da Maria Bonita e Lampião, farão com que a memória persista por longo tempo, sobretudo numa época em que as memórias são encapsuladas em cartões magnéticos, logo transformadas em pixels, a trafegar nas infovias. De outra parte, o poder de vínculo que a música exerce é forte. Durarão mais tempo os cartões postais sonoros que os antigos cartões em papelão, ou gozarão a mesma vida efêmera que as notícias dos blogs das redes sociais? Qualquer possível resposta para essa pergunta parece apontar que, a despeito de todas novas mudanças que venham a ocorrer nesse empreendimento que se tornou o pôr-do-sol na praia do Jacaré, o Bolero, de Maurice Ravel continuará a render novos signos, em qualquer latitude ou período do dia. Quanto ao Jurandy, pode-se dizer que soube tirar proveito das possibilidades que a tecnologia da informação lhe oferece, resultando em benefícios empresariais.

\section{Referências}

BOLÉRO (Ravel) - André Rieu. [S. l.: s. n.], 24 abr. 2012. 1 vídeo (ca. 7 min). Publicado pelo canal André Rieu. Disponível em: https://www.youtube.com/watch?v=LwLABSm0yYc. Acesso em: 10 ago. 2014

GOLÉA, Antoine. BOLERO. In: LAROUSSE de la Musique. Paris: Librairie Larousse, 1982. v. $1 / 2$.

CALLIGARIS, Contardo. Volta com pôr do sol. Folha de São Paulo, São Paulo, p. 2, 28 jan. 2010.

FELIX, José Jurandir. Jurandir do Sax, famoso por tocar Bolero de Ravel, conversa com Jô Soares. [Entrevista cedida a] Jô Soares. [S. l.]: Globoplay, 13 set. 2011. 1 vídeo (18 min). Programa do Jô. Disponível em: http://globotv.globo.com/rede-globo/programa-dojo/v/jurandir-do-sax-famoso-por-tocar-bolero-de-ravel-conversa-com-jo-soares/1629425/. Acesso em: 10 ago. 2014.

JURANDIR do Sax declara 'Luto' e diz que remoção de restaurantes no Jacaré é destruição do turismo. Portal do litoral PB, [s. l.], 4 ago. 2014. Disponível em: http://www.portaldolitoralpb.com.br/jurandir-do-sax-declara-luto-e-diz-que-remocao-derestaurantes-no-jacare-e-destruicao-do-turismo. Acesso em: 28 maio 2017.

JURANDY do Sax. João Pessoa, [2018]. Facebook: @JurandydoSaxpb. Disponível em: https://www.facebook.com/JurandydoSaxpb. Acesso em: 10 jul. 2018. 
JURANDY DO SAX: http://jurandydosax.com.br/. Acesso em 10 jul. 2018.

RAVEL - Bolero. Sergiu Celibidache 1971. [S. l.: s. n.], 2 nov. 2011. 1 vídeo (ca. 1 min). Publicado pelo canal Miclu2011. Disponível em: https://www.youtube.com/watch? $\mathrm{v}=$ gy5Ve3338-E. Acesso em: 10 ago. 2014.

RAVEL - Bolero. Sergiu Celibidache 1971. [S. l.: s. n.], 2 nov. 2011. 1 vídeo (ca. 1 min).

VALENTE, Heloísa de A. D. As vozes da canção na mídia. São Paulo: Via Lettera, 2003.

WIENER Philharmoniker - Maurice Ravel - Bolero - Regente Gustavo Dudamel. [S. l.: s. n.], 24 set. 2018. 1 vídeo (ca. 17 min). Publicado pelo canal Charles Henrique da Silva. Disponível em: https://www.youtube.com/watch?v=mhhkGyJ092E. Acesso em: 25 set. 2019.

WIENER Philharmoniker - Maurice Ravel - Bolero - Regente Gustavo Dudamel. [S. l.: s. n.], 24 set. 2018. 1 vídeo (ca. $17 \mathrm{~min}$ ). Publicado pelo canal Charles Henrique da Silva. Disponível em: https://www.youtube.com/watch?v=mhhkGyJ092E. Acesso em: 25 set. 2019

ZUMTHOR, Paul. Escritura e nomadismo. São Paulo: Ateliê Editorial, 2005.

ZUMTHOR, Paul. Introdução à poesia oral. São Paulo: HUCITEC, 1997.

\section{Jurandy surfs on an alligator playing Ravel's Bolero}

The present text intends to analyze the event known as "sunset at Alligator beach", in Cabedelo (PB), with Ravel's Bolero as background music, created by the musician most known as "Jurandy of the Sax". We intend to analyze the appropriation forms of the musical work, converted into object of local touristic consumption. For this purpose, we will analyze the mouvance processes of Ravel's work through different performances and distinctive aesthetic conceptions. The strategies adopted by Jurandy, serve as symbolic elements of reinforcement in his interaction with the public. At the same time, the creation of Jurandy is emphasized as the establishment of a peculiar sound landscape. Among the conclusions, the importance of the musician in the self-promotion of his products, besides the creation of a lode of media consumption of the music by the tourism stands out.

\section{Keywords}

Soundscape. Performance. Ravel's Bolero. Entertainment. Sonorous postcards.

Recebido em 10/07/2018

Aceito em 29/05/2019 